\begin{tabular}{|c|l|}
\hline Title & $\begin{array}{l}\text { A potential glucuronate glycosyl donor with 2-0-acyl-6,3lactone structure: efficient synthesis of glycosaminoglycan } \\
\text { disaccharides }\end{array}$ \\
\hline Author(s) & Furukawa, Takayuki; Hinou, Hiroshi; Shimawaki, Ken; Nishimura, Shin-Ichiro \\
\hline Citation & $\begin{array}{l}\text { Tetrahedron Letters, 52(43), 5567-5570 } \\
\text { https://doi.org/40.1016/.tetlet.2011.08.024 }\end{array}$ \\
\hline Issue Date & 2011-10-26 \\
\hline Doc URL & http://hdl.handle.net/2115/47554 \\
\hline Type & article(author version) \\
\hline File Information & TL52-43_5567-5570.pdf \\
\hline
\end{tabular}

Instructions for use 


\section{Graphical Abstract}

To create your abstract, type over the instructions in the template box below.

Fonts or abstract dimensions should not be changed or altered.

A Potential Glucuronate Glycosyl Donor
with 2-O-acyl-6,3-lactone Structure: Efficient
Synthesis of Glycosaminoglycan
Disaccharides
Takayuki Furukawa, Hiroshi Hinou*, Ken Shimawaki and Shin-Ichiro Nishimura




\title{
A Potential Glucuronate Glycosyl Donor with 2-O-acyl-6,3-lactone Structure: Efficient Synthesis of Glycosaminoglycan Disaccharides
}

\author{
Takayuki Furukawa, Hiroshi Hinou*, Ken Shimawaki, and Shin-Ichiro Nishimura \\ Graduate School of Life Science and Frontier Research Center for Post-Genome Science and Technology, Hokkaido University, N21, W11, Kita-ku, Sapporo 001-0021, Japan
}

\section{ARTICLE INFO}

Article history:

Received

Received in revised form

Accepted

Available online

Keywords:

Glycosylation

Lactones

Carbohydrate

Glycosaminoglycans

1,2-trans stereoselectivity

Uronic acids are an important class of monosaccharides and are defined as aldohexoses in which primary alcohol is oxidized to a carboxylic acid. Polysaccharides containing uronic acid entities are widespread in nature and display an array of physical properties and biological functions. ${ }^{1}$ For example, glycosaminoglycans (GAGs) are ubiquitous components of the extracellular matrix and play essential roles in biological systems. ${ }^{2}$ Because of irregular modifications of their skeleton, structurally defined GAG fragments are not easily prepared from natural resources. Thus, novel and efficient methods of the preparation of GAG fragments are crucial to advance our understandings of this important class of biomolecules. Extensive efforts have been made to improve the synthesis of oligosaccharides containing uronic acids. ${ }^{3}$ However, the low reactivity of uronic acid derivatives as glycosyl donors in chemical glycosylation steps has impeded progress. This low reactivity results from the electron withdrawing property of the carboxylate group. ${ }^{4}$ Currently, the following two strategies have been adopted to overcome this problem: i) "post-glycosylation oxidation ${ }^{4 \mathrm{~b}, 5}$ ": constructing glycosides followed by an oxidation and ii) "arming" the reactivity by the arrangement of protecting groups. ${ }^{6}$ Conformational arming effect ${ }^{7}$ is also an attractive concept for the activation of uronate donors. Van der Marel et al. demonstrated glycosylation reactions of a galacturonate-type donor whose conformation was locked by 6,3 -lactone bridge ${ }^{8}$ to give 1,2-cis glycoside by using the reduced reactivity by the torsional effect $^{9}$ of the 6,3-lactone ${ }^{8 \mathrm{a}}$ and high reactivity as glycosyl acceptor ${ }^{8 b}$. They also prepared the 6,3-lactone type donor of gluc- and mannuronate. ${ }^{8}$ However, they did not demonstrate any conformational arming effect of this class of donor and used common ${ }^{4} \mathrm{C}_{1}$ type uronate donors in the following studies of glycosylations. ${ }^{6 \mathrm{~d}, \mathrm{e}}$
Hence, we designed glucuronate derivative $\mathbf{1}$ as a key synthon for synthesis of GAGs fragments (Fig. 1), since GAGs contain the $\beta$-GlcA moiety in repeating disaccharide units. The conformation of $\mathbf{1}$ is fixed by a 6,3-lactone bridge in ${ }^{1} \mathrm{C}_{4}$, with all substituents in an axial orientation. ${ }^{4 b, 10}$ In more axial rich conformation, the reactivity increase is expected due to the different mode of $\sigma-\sigma^{*}$ or dipole interactions. ${ }^{7,11}$ Also, to enhance 1,2-trans stereoselectivity, to suppress side reactions in coupling steps, and to enhance the activation of the thioglycoside, we selected a well-used 2-O-acyl protection to employ neighboring group participation. ${ }^{12}$ In addition, the rigid 3,6-lactone structure might also activate the orthoester-type intermediate formed by the participation of the 2-O-acyl group on donor $\mathbf{1}$.

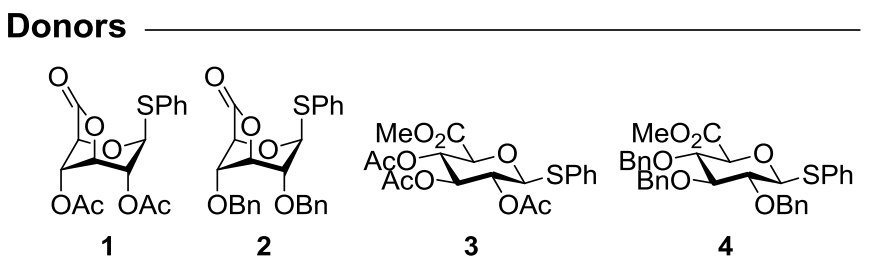

Acceptors
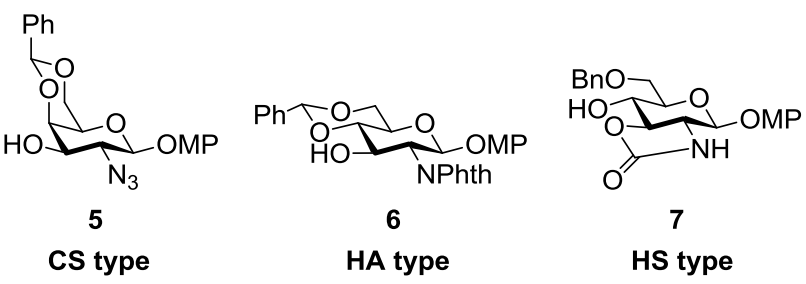

Figure 1. donors and acceptors employed in this study. MP: $p$-methoxy phenyl. 
Tetrahedron Letters

To investigate the efficiency of our strategy, we prepared $\mathbf{1}$, $O$-benzyl protected glucuronolactone derivative $\mathbf{2}^{8}$, and a corresponding set of standard methyl glucuronate derivatives $\mathbf{3}^{13}$ and $\mathbf{4}^{14}$ as disarmed and armed counterparts with ${ }^{4} \mathrm{C}_{1}$ conformation, respectively. As acceptors, hexosamine derivatives $5^{15}, 6^{16}$ and $7^{17}$ were prepared to afford chondroitin sulfate (CS), hyaluronic acid (HA), and heparan sulfate (HS) type dissaccharide units in GAGs, respectively. (Fig. 1)

The simultaneous lactonization with C6-oxidation ${ }^{8}$ of $\mathbf{8}$ using 2,2,6,6-tetramethylpiperidinyloxy free radical (TEMPO) and [bis(acetoxy)iodo]benzene (BAIB) reagent system ${ }^{18}$ afforded 6,3lactone donor 1 only in $22 \%$ but uncyclized derivative 9 in $73 \%$ yield. EDC/HOBt system, however, was found to give the lactone $\mathbf{1}$ in $93 \%$ from 9 . (Scheme 1)
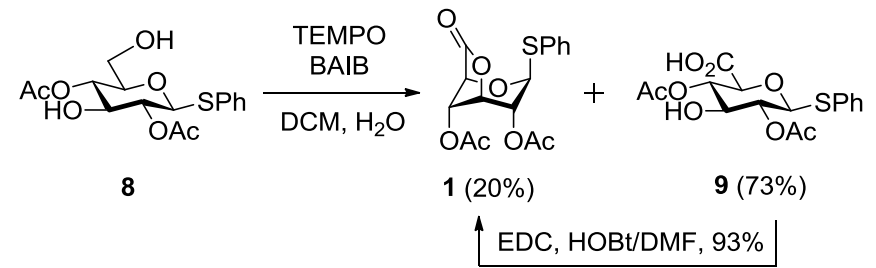

Scheme 1. Synthesis of lactone donor 1.

Table 1. Glycosylations with $\mathrm{GalN}_{3}$ derivative 5 under NIS/TfOH system

\begin{tabular}{|c|c|c|c|c|}
\hline \# & donor & Conditions $^{\mathrm{a}}$ & 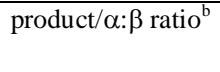 & $\begin{array}{l}\text { Yield } \\
(\%)^{\mathrm{c}}\end{array}$ \\
\hline 1 & 1 & 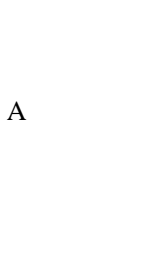 & OAc OAc 10 & quant. \\
\hline 2 & 2 & A & OBn OBn & $\operatorname{trace}^{\mathrm{d}}$ \\
\hline 3 & 3 & A & $\begin{array}{r}\text { OAc } \\
12\end{array}$ & 83 \\
\hline 4 & 4 & A & $\begin{array}{l}\text { OBn } \\
13(\alpha:)\end{array}$ & 67 \\
\hline 5 & 1 & B & OAc & 68 \\
\hline 6 & 2 & B & 11 & $\operatorname{trace}^{\mathrm{d}}$ \\
\hline 7 & 4 & B & $13(\alpha: \beta=2: 3)$ & 93 \\
\hline
\end{tabular}

${ }^{\mathrm{a}}$ (A) donor (1.5 eq.), acceptor (1.0 eq.), NIS (1.5 eq.), TfOH (0.2 eq.), DCM $(0.07 \mathrm{M}),-40^{\circ} \mathrm{C}, 1 \mathrm{~h}$, then $-10^{\circ} \mathrm{C}, 1 \mathrm{~h}$; (B) donor (1.2 eq.), acceptor (1.0 eq.), NIS (1.2 eq.), TfOH (0.2 eq.), DCM $(0.1 \mathrm{M}),-40^{\circ} \mathrm{C}, 2 \mathrm{~h}$.

${ }^{\mathrm{b}}$ Isolated ratio.
Table 1 shows the result of glycosylation reactions of the glycosyl donors $\mathbf{1 - 4}$ with D-galactosamine derivative $\mathbf{5}$ as an acceptor substrate. The diacetyl-protected donor $\mathbf{1}$ under the promotion with NIS/TfOH at $-40{ }^{\circ} \mathrm{C}$ and stirring at $-10^{\circ} \mathrm{C}$ for $1 \mathrm{~h}$ afforded CS-type disaccharide $\mathbf{1 0}$ in a quantitive yield. (\# 1) Meanwhile, the glycosylation of dibenzyl-protected donor $\mathbf{2}^{8}$ provided a trace amount of disaccharide 11. (\# 2) Interestingly, this donor 2 was found extremely fragile to be used as a donor substrate even at $-40{ }^{\circ} \mathrm{C}$. (\# 6) Analyses of the major product from donor 2 suggested that de-benzylation at O-4 seemed to be proceeded, although the exact structure could not be identified. When ${ }^{4} \mathrm{C}_{1}$ type donor 3 was employed, the corresponding $\beta$ linked disaccharide $\mathbf{1 2}$ was obtained in $83 \%$ yield. (\# 3) Unexpectedly, an armed counterpart 4 afforded disaccharide $\mathbf{1 3}$ in $67 \%$ yield with a slight $\alpha$-selectivity. (\# 4) When the reaction of donor 1 was performed under the conventional condition B (quenched at $-40{ }^{\circ} \mathrm{C}$ ), orthoester $\mathbf{1 4}$ was identified as the main product and $24 \%$ of acceptor 5 was recovered. (\# 5) In the case of donor 4 without elevating temperature, the coupling product $\mathbf{1 3}$ was isolated in $93 \%$ yield as a slight $\beta$-rich mixture. (\# 7) The result of \# 1 and 5 indicates that a glycosidic bond was formed via orthoester, and product $\mathbf{1 0}$ was stable to an acid catalyst at $10{ }^{\circ} \mathrm{C}$. In contrast, from the result of \# 4 and 7 , disaccharide especially $\beta$-glycoside may be unstable under the condition A.

To confirm the versatility of 6,3-lactone and 2-O-acyl substituents, we carried out reactions of glucosamine derivative 6 as an acceptor substrate to afford HA type disaccharide. (Table 2, \# 1-4) The coupling of donor $\mathbf{1}$ and acceptor $\mathbf{6}$ under an optimized condition afforded $\beta$-linked disaccharide 15 quantitively. (\# 1) Meanwhile, when ${ }^{4} \mathrm{C}_{1}$ donor 3 was employed, disaccharide 16 was obtained only in $22 \%$ yield. (\# 2) The glycoside 17 which was obtained from the donor 4 was also unstable at $-10^{\circ} \mathrm{C}$. (\# 3) By keeping the reaction at $-40^{\circ} \mathrm{C}$, however, disaccharide 17 was isolated quantitively with a slight increase of $\beta$-selectivity. (\# 4) Thus, the remarkable high yield, $\beta$-selectivity, and stability under acidic conditions of glycoside $\mathbf{1 5}$ clarified the advantage of donor 1.

In the last place, synthesis of HS type disaccharide was evaluated by using a 2,3-carbamate protected glucosamine derivative 7 as an acceptor which can apply to a donor for $\alpha$ selective glycosylation ${ }^{19}$ at farther glycosylation steps. (\# 5-8) Glycosylation reaction to 4-OH of $N$-acetylglucosamine derivatives is a well-known challenge because of the poor nucleophilicity. ${ }^{20}$ Indeed, the coupling of donor $\mathbf{1}$ and acceptor $\mathbf{7}$ at $-10{ }^{\circ} \mathrm{C}$ gave HS-type disaccharide 18 only in $22 \%$ yield. (\# 5) Analysis of this reaction revealed the existence of orthoester at $10{ }^{\circ} \mathrm{C}$. This fact suggested that the conversion to the glycoside was incomplete. Tracing the reaction at $0{ }^{\circ} \mathrm{C}$ identified that the orthoester disappeared in 3 hours and the $\beta$-glycoside $\mathbf{1 8}$ was isolated in $63 \%$ yield. (\# 6) The yield was still moderate but enough for the fragment synthesis as in previous excellent studies. ${ }^{4 \mathrm{~b}, 21}$ As expected, a donor $\mathbf{3}$ with acetyl group at O-2 afforded $\beta$-linked disaccharide 19 only in $18 \%$ yield. (\# 7) Interestingly, disaccharide 20 was stable even at $0{ }^{\circ} \mathrm{C}$ and the yield was $93 \%$ yield as a $\alpha$-rich mixture. (\# 8)

In summary, we designed a novel glucuronate donor with 6,3lactone and 2-O-acyl protection for the construction of glucuronic acid-containing entities. The 6,3-lactone donor $\mathbf{1}$ demonstrated an excellent versatility via a series of GAGs disaccharide syntheses. In particular, ideal $\beta$-selectivities, high yields, and stable glycosides are noteworthy features. Therefore, we believe that donor $\mathbf{1}$ provides a practical approach to prepare various glycosides and glycoconjugates containing unonate moieties. Currently, further application of this glucuronate donor for longer GAG oligosaccharide synthesis is in progress.

bator.

${ }^{\mathrm{d}}$ Detected only by MALDI-TOF MS. 
We thank S. Oka at the Center for Instrumental Analysis, Hokkaido University, for ESI-MS measurement. This work was supported partly by a grant for a "Promotion for Young Research Talent and Network" from Northern Advancement Center for Science \& Technology (NOASTEC) and "Innovation COE Program for Future Drug Discovery and Medical Care" from the
Ministry of Education, Culture, Science, Sports and Technology of Japan.

Table 2. Glycosylation with glucosamine derivatives 6 and 7 under NIS/TfOH system

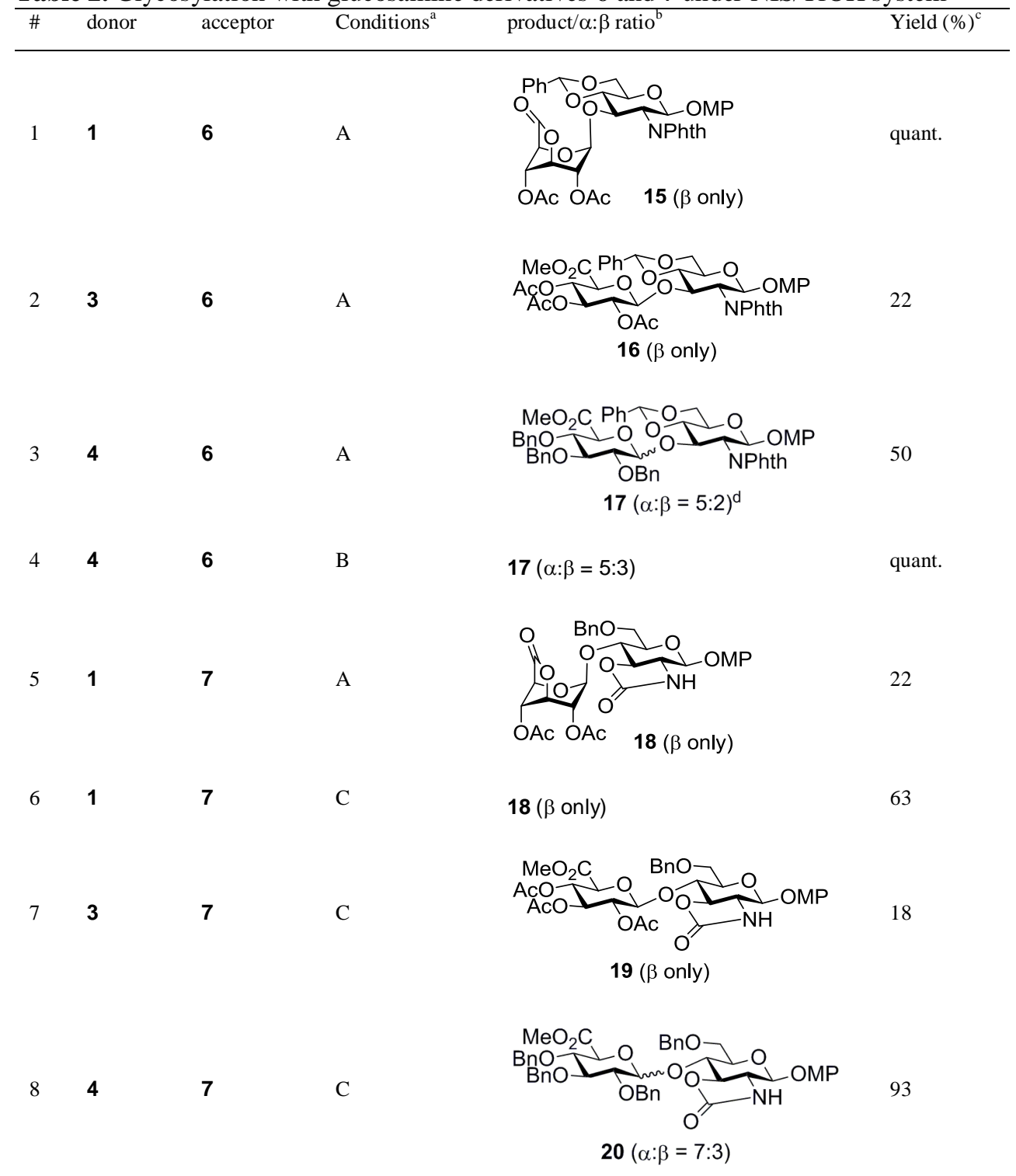

$\overline{\mathrm{a}}$ (A) donor (1.5 eq.), acceptor (1.0 eq.), NIS (1.5 eq.), TfOH $\left(0.2\right.$ eq.), DCM $(0.07 \mathrm{M}),-40^{\circ} \mathrm{C}, 1 \mathrm{~h}$, then $-10^{\circ} \mathrm{C}, 1 \mathrm{~h}$; (B) donor (1.2 eq.), acceptor $(1.0$ eq. $), \mathrm{NIS}$ (1.2 eq.), TfOH (0.2 eq.), DCM $(0.1 \mathrm{M}),-40{ }^{\circ} \mathrm{C}, 2 \mathrm{~h}$; (C) donor (1.5 eq.), acceptor (1.0 eq.), NIS (1.5 eq.), TfOH $(0.2$ eq. $), \mathrm{DCM}(0.07 \mathrm{M}),-40{ }^{\circ} \mathrm{C}, 2 \mathrm{~h}$, then $0{ }^{\circ} \mathrm{C}$, $3 \mathrm{~h}$.

${ }^{\mathrm{b}}$ Isolated ratio.

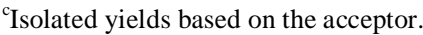

${ }^{\mathrm{d}}$ Determined by ${ }^{1} \mathrm{H}-\mathrm{NMR}$ analysis.

\section{References and notes}

1. (a) Smelcerovic, A.; Knezevic-Jugovic, Z.; Petronijevic, Z. Curr Pharm Des. 2008, 14, 3168-3195. (b) Baldwin, A. D.; Kiick, K. L. Biopolymers. 2010, 94, 128-140.

2. (a) Edward, C. H. Trends in Glycoscience and Glycotechnology. 1998, 10, 51-56. (b) Petitou, M.; Van Boeckel, C. A. A. Angew. Chem. Int. Ed. Engl. 2004, 43, 3118-3133.

3. (a) Noti, C.; Seeberger, P. H. Chem. Biol. 2005, 12, 731-756. (b) Karst, N. A.; Linhardt, R. J. Curr. Med. Chem. 2003, 10, 19932031.

4. (a) Zeng, Y.; Wang, Z.; Whitfield, D.; Huang, X. J. Org. Chem. 2008, 73, 7952-7962. (b) van den Bos, L. J.; Codée, J. D. C.;
Litjens, R. E. J. N.; Dinkelaar, J.; Overkleeft, H. S.; van der Marel, G. A. Eur. J. Org. Chem. 2007, 24, 3963-3976.

5. Haller, M.; Boons, G. J. J. Chem. Soc., Perkin Trans. 1. 2001 , 814-822.

6. (a) Mootoo, D. R.; Konradsson, P.; Udodong, U.; Fraser-Reid, B. J. Am. Chem. Soc. 1988, 110, 5583-5584. (b) Zhang, Z.; Ollmann, I. R.; Ye, X. S.; Wischnat, R.; Baasov, T.; Wong, C. H. J. Am. Chem. Soc. 1999, 121, 734-753. (c) Mydock, L. K.; Demchenko, A. V. Org. Lett. 2008, 10, 2103-2106. (d) Dinkelaar, J.; Codée, J. D. C.; van den Bos, L. J.; Overkleeft, H. S.; van der Marel, G. A. J. Org. Chem. 2007, 72, 5737-5742. (e) Dinkelaar, J.; Gold, H.; Overkleeft, H. S.; Codée, J. D. C.; van der Marel, G. A. J. Org. Chem. 2009, 74, 4208-4216.

7. (a) Poláková, M.; Pitt, N.; Tosin, M,; Murphy, P. V. Angew. Chem. Int. Ed. Engl. 2004 , 43 , 2518 -2521. (b) Pedersen, C. M.;

Nordstrøm, L. U.; Bols, M. J. Am. Chem. Soc. 2007, 129, $9222-$ 


\section{Tetrahedron}

9235. (c) Jensen, H. H.; Pedersen, C. M.; Bols, M. Chem. Eur. J.

2007, 13, 7576-7582. (d) Pedersen, C. M.; Marinescu, L. G.; Bols,

M. Chem. Commun. 2008, 2465-2467. (e) Pedersen, C. M.;

Marinescu, L. G.; Bols, M. Comptes Rendus Chimie. 2011, 14,

$17-43$.

8. (a) van den Bos, L. J.; Litjens, R. E. J. N.; van den Berg, R. J. B.

H. N.; Overkleeft, H. S.; van der Marel, G. A. Org. Lett. 2005, 7,

2007-2010. (b) Christina, A. E.; van den Bos, L. J.; Overkleeft, H. S.; van der Marel, G. A.; Codée, J. D. C. J. Org. Chem. 2011, 76, 1692-1706.

9. (a) Grice, P.; Ley, S. V.; Pietruszka, J.; Osborn, H. M. I.; Priepke, H. W. M.; Warriner, S. L. Chem. Eur. J. 1997, 3, 431-440. (b) Douglas, N. L.; Ley, S. V.; Lücking, U.; Warriner, S. L. J. Chem. Soc., Perkin Trans. 1. 1998, 51-66. (c) Crich, D.; De la Mora, M.; Vinod, A. U. J. Org. Chem. 2003, 68, 8142-8148. (d) Jensen, H. H.; Nordstrøm, L. U.; Bols, M. J. Am. Chem. Soc. 2004, 126, 9205-9213.

10. (a) Chernyak, A. Y.; Kononov, L. O.; Kochetkov, N. K. Carbohydr. Res. 1991, 216, 381-398. (b) Kornilov, A. V.;

Sherman, A. A.; Kononov, L. O.; Shashkov, A. S.; Nifant'ev, N. E. Carbohydr. Res. 2000, 329, 717-730.

11. (a) McDonnell, C.; López, O.; Murphy, P.; Fernández Bolaños, J. G.; Hazell, R.; Bols, M. J. Am. Chem. Soc. 2004, 126, 1237412385. (b) Jensen, H. H.; Bols, M. Acc. Chem. Res. 2006, 39, 259265.

12. (a) Hünig, S. Angew. Chem., Int. Ed. Engl. 1964, 3, 548. (b) Fife, T. H.; Bembi, R.; Natarajan, R. J. Am. Chem. Soc. 1996, 118, 12956-12963. (c) T, Nukada.; A, Berces.; Zgierski, M. Z.; Whitfield, D. M. J. Am. Chem. Soc. 1998, 120, 13291-13295. (d) Premathilake, H. D.; Mydock, L. K.; Demchenko, A. V. J. Org. Chem. 1999, 64, 293-295.

13. Ferrier, R. J.; Furneaux, R. H. Carbohydr. Res. 1976, 52, 63-68.

14. Codée, J. D. C.; van den Bos, L. J.; De Jong, A. R.; Dinkelaar, J.; Lodder, G.; Overkleeft, H. S.; van der Marel, G. A. J. Org. Chem. 2009, 74, 38-47.

15. Mukherjee, C.; Misra, A. K. Tetrahedron: Assymmetry. 2008, 19 , 2746-2751.

16. (a) Sakamoto, J.; Mullen, K. Org. Lett., 2004, 6, 4277-4280. (b) Davis, B. G. PCT/GB2007/000398, 2007.

17. See supporting information; Scheme 2 .

18. (a) Epp, J. B.; Widlanski, T. S. J. Org. Chem. 1999, 64, 293-295.

(b) De Mico, A.; Margarita, R.; Parlanti, L.; Vescovi, A.; Piancatelli, G. J. Org. Chem. 1997, 62, 6974-6977.

19. (a) Benakli, K.; Zha, C.; Kerns, R. J. J. Am. Chem. Soc. 2001, 123, 9461-9462. (b) Crich, D.; Vinod, A. U. Org. Lett. 2003, 5, $1297-$ 1300. (c) Manabe, S.; Ishii, K.; Ito, Y. J. Am. Chem. Soc. 2006, 128, 10666-10667.

20. (a) Crich, D.; Dudkin, V. J. Am. Chem. Soc. 2001, 123, 6819-6825. (b) Miermont, A.; Zeng, Y.; Jing, Y.; Ye, X. -S.; Huang, X. J. Org. Chem. 2007, 72, 8958-8961. (c) Paulsen, H. Angew. Chem. Int. Ed.. 1982, 21, 155-173.

21. (a) Orgueira, H. A.; Bartolozzi, A.; Schell, P.; Litjens, R. E. J. N.; Palmacci, E. R.; Seeberger, P. H. Chem. Eur. J. 2003, 9, 140-169. (b) van den Bos, L. J.; Codée, J. D. C.; van der Toorn, J. C.; Boltje, T. J.; van Boom, J. H.; Overkleeft, H. S.; van der Marel, G. A. Org. Lett. 2004, 6, 2165-2168. 